\title{
Short-Burst Bipolar Coagulation for Repairing Partially Damaged Brain Arteries Preserving Their Flow : Technical Note
}

\section{Choque-Velasquez, Joham}

2016

Choque-Velasquez, J , Colasanti , R, Jahromi , B R, Rafei , A, Sharafeddin , F \& Hernesniemi , J 2016 , ' Short-Burst Bipolar Coagulation for Repairing Partially Damaged Brain Arteries Preserving Their Flow : Technical Note ', World Neurosurgery, vol. 93 , pp. 324-329 . https://doi.org/10.1016/j.wneu.2016.06.013

http://hdl.handle.net/10138/231305

https://doi.org/10.1016/j.wneu.2016.06.013

publishedVersion

Downloaded from Helda, University of Helsinki institutional repository.

This is an electronic reprint of the original article.

This reprint may differ from the original in pagination and typographic detail.

Please cite the original version. 


\title{
Short-Burst Bipolar Coagulation for Repairing Partially Damaged Brain Arteries Preserving Their Flow: Technical Note
}

\author{
Joham Choque-Velasquez ${ }^{1}$, Roberto Colasanti ${ }^{1,2}$, Behnam Rezai Jahromi ${ }^{1}$, Ahmadreza Rafei ${ }^{1}$, Fransua Sharafeddin ${ }^{1}$, \\ Juha Hernesniemi ${ }^{1}$
}

OBJECTIVE: Preservation of the integrity of perilesional and intralesional arteries, as well as of perforating vessels, is of utmost importance in microneurosurgery. The purpose of our study was to describe our adaptation of the shortburst bipolar coagulation technique, which was initially introduced by Professor Yasargil, for repairing partially damaged brain arteries.

METHODS: When a brain artery is partially and inadvertently damaged during microneurosurgical procedures, microscope magnification is further increased from the high magnification that is routinely used $(10-15 \times)$ up to $14-17 \times$ in order to recognize clearly the injured zone of the vessel. Then the exact bleeding point is identified with a precise suction. Next, bipolar forceps with sharp tips $\mathbf{0 . 3}$ $\mathrm{mm}$ ) are used to seal the wall of the injured artery, closing the borders of the hole between them. A delicate coagulation (20 Malis units, 3 watts) is performed for less than a second according to the so-called "open-close" technique. Short and small bursts of coagulation are used to progressively reduce the size of the defect by cauterization of the surrounding tissue. This gradually diminishes the bleeding up to restore the functional integrity of the vessel wall.

RESULTS: The senior author's modification of the Yasargil technique has been used for more than 30 years as a simple and fast method of microsurgical vascular repair of small tears.

CONCLUSIONS: The bipolar coagulation represents a safe, clean, fast, and even cheap method for repairing wall defects in fine arteries that are accidently damaged during a microsurgical operation.

\section{INTRODUCTION}

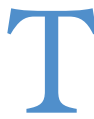

he preservation of normal perilesional and intralesional arteries, as well as of perforating branches, is crucial in every microneurosurgical operation. Their protection may require extremely high precision and tedious work, but this is essential to achieve an optimal result. If an artery is accidentally injured, its flow should be immediately restored in order to prevent postoperative complications such as cerebral ischemia, hemorrhagic infarction, and even death in some cases. ${ }^{1-8}$

Various surgical procedures (such as microsuture, bypass technique, wrapping, microvascular clip placement, or AnastoClips) have been used for dealing with intraoperative arterial rupture. Suturing techniques may be time consuming and are associated with potential ischemic complications that are proportional to the occlusion time for repair. Moreover, a vessel's patency may be compromised with subsequent thrombosis. The main advantages of nonsuturing techniques are shorter operative times, better access to narrow and deep surgical corridors, and reduced intimal injury. ${ }^{9-12}$ However, all of the these techniques may not be as effective in dealing with fine tears of very small vessels.

The microsurgical vascular repair of small tears using the bipolar coagulation was introduced by Professor Yasargil in the 1960s. In his method, suction and compression with a pledget are used to identify the bleeding site, which is subsequently sealed by bipolar coagulation. If bleeding persists despite these maneuvers, temporary microvascular clips are applied (first only proximally and

\section{Key words \\ - Bipolar coagulation \\ - High magnification \\ - Microneurosurgery \\ - Neurosurgical practice \\ - Surgical techniques \\ - Vascular repair}

From the ${ }^{1}$ Department of Neurosurgery, Helsinki University Central Hospital, Helsinki, Finland; and ${ }^{2}$ Department of Neurosurgery, Umberto I General Hospital, Università Politecnica delle Marche, Ancona, Italy
To whom correspondence should be addressed: Joham Choque-Velasquez, M.D. [E-mail: johchove@hotmail.com]

Citation: World Neurosurg. (2016) 93:324-329.

http://dx.doi.org/10.1016/j.wneu.2016.06.013

(-) Supplementary digital content available online.

Journal homepage: www.WORLDNEUROSURGERY.org

Available online: www.sciencedirect.com

1878-8750/\$ - see front matter ( 2016 Elsevier Inc. All rights reserved. 
then distally, if required), before the tear in the artery wall is repaired by bipolar coagulation or microsuture. 1,13,14

In 1982 the senior author (J.H.) visited the Department of Neurosurgery at the Zurich University Hospital. Since then, this technique was adapted and used to perform more than 15,000 surgeries in 30 years (Figure 1).

The aim of this report is to present our strategy for the application of this elegant technique that well exemplifies the general philosophy of Helsinki microneurosurgery: "simple, clean, fast, and preserving normal anatomy."

\section{SHORT-BURST BIPOLAR COAGULATION TECHNIQUE}

This technique does not need special equipment; the basic set of Professor J. Hernesniemi includes the usual microsurgical instruments, specifically bipolar regular stainless steel forceps (with sharp tips [0.3 mm] for delicate coagulation [20 Malis units, 3 watts (W)] or blunt tips for medium, straight-caliber vessels [25 Malis units, $5 \mathrm{~W}$ )), a suction tube (with 3 holes at its base that enable controlling the suction force by sliding the thumb), and a

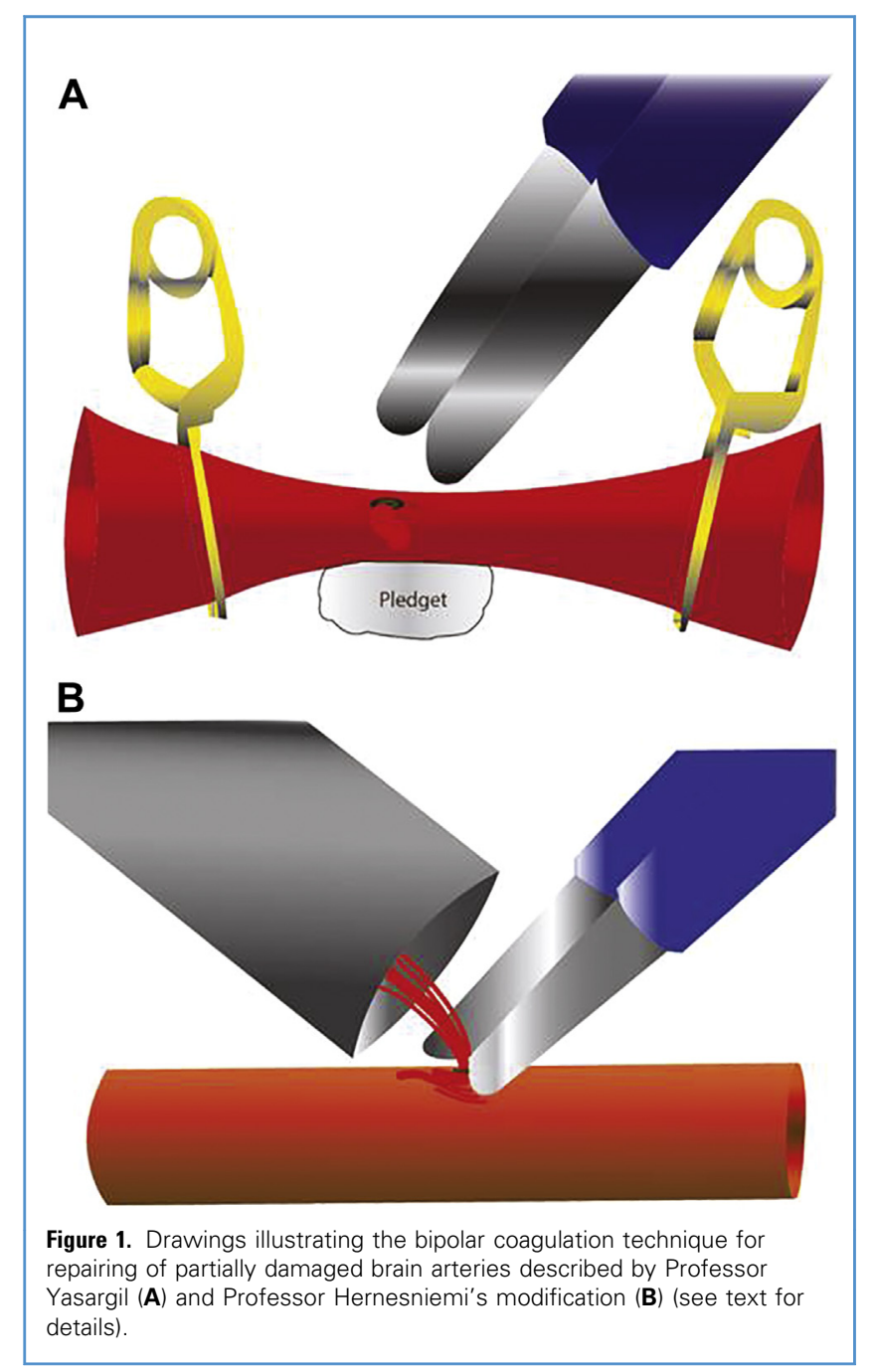

handheld syringe for focused saline irrigation (if it is needed to clean the surgical field) (Figure 2). 2,3

Despite a careful and meticulous microneurosurgical dissection, sometimes the walls of fine perilesional and intralesional arteries, as well as of perforating branches, may be partially and inadvertently damaged, producing a small tear in the vessel or more copious and risky bleeding.

In such troublesome circumstances, the following steps are required:

1). Microscope magnification is further increased from the high magnification that is routinely used $(10-15 \times)$ up to $14-17 \times$ in order to recognize clearly the injured zone of the vessel. $2,3,15$

2). Then, the exact bleeding point is identified with a precise suction; a focused saline irrigation is applied just if this is necessary to clean the surgical field as it may disturb the view. Temporary clips are not used regularly, but sometimes a small pledged may be useful. The adjustment of the strength of the suction usually allows the surgeon to control bleeding in most cases (Figure 3). ${ }^{13,16,17}$

3). Once the bleeding is going straight into the suction tube, bipolar forceps with sharp tips $(0.3 \mathrm{~mm})$ are used to seal the wall of the injured artery, closing the borders of the hole between them while the blood flow maintains the normal diameter of the vessel.

4). A delicate coagulation (20 Malis units, 3 Watts) is performed for less than a second according to the so-called "openclose" technique. In this step, a precise activation/deactivation of the bipolar device is of utmost importance: This requires good "eye-hand-foot coordination," or an accurate teamwork with the scrub nurse if he or she has the control of the bipolar foot pedal. Bipolar forceps with blunt tips (25 Malis units, 5 Watts) may be used for straight, medium-caliber vessels. ${ }^{18-20}$

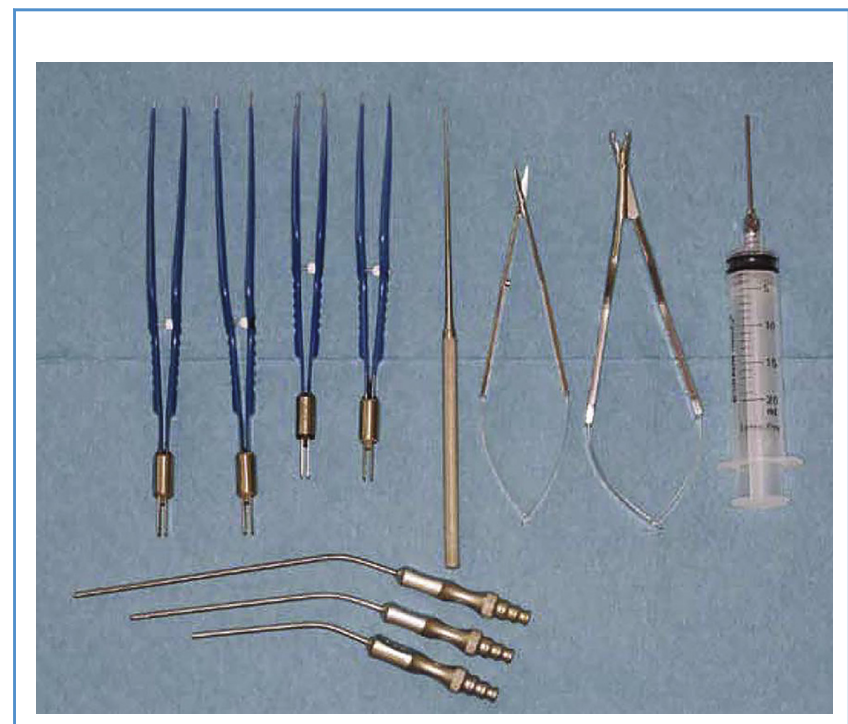

Figure 2. The basic set of Professor Juha Hernesniemi. 


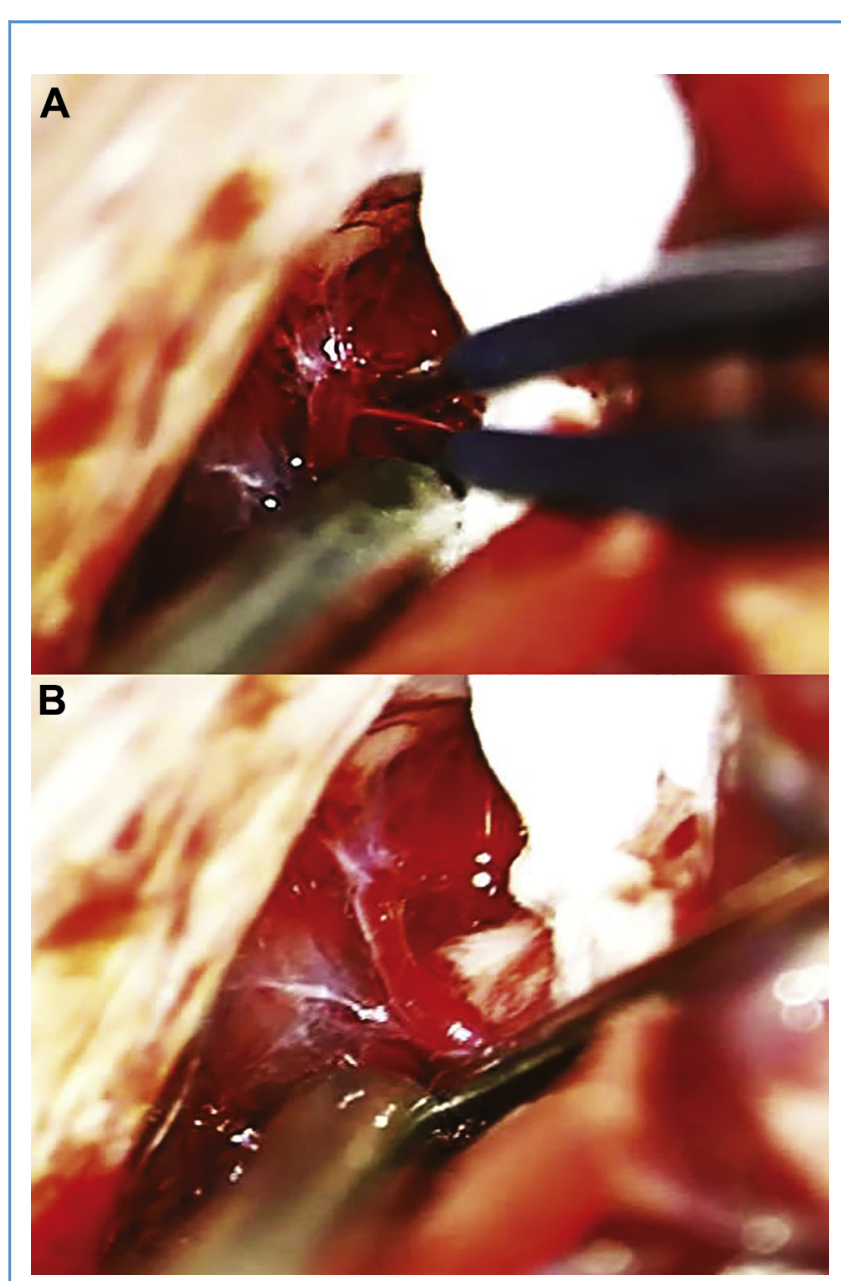

Figure 3. Intraoperative microscopic photographs illustrating the bipolar coagulation technique for a small perforating branch from right A3, inadvertently damaged during an interhemispheric approach (A). Ten short bursts of coagulation allowed the surgeon to completely seal the vessel wall defect (B). coagulation technique was then performed to repair this fine artery. Ten short bursts of coagulation during 60 seconds were necessary to completely seal the vessel without evidence of vascular stenosis or collapse (Figures 3 and 4) (see Video, Supplemental Digital Content 1, demonstrating the bipolar coagulation technique to repair a partially damaged perforating branch from right $A 3$ ).

\section{Illustrative Case 2}

A 55-year-old man with a left temporal high-grade glioma underwent a left temporal craniotomy and removal of the lesion. A small left temporal M2-M3 branch was accidentally damaged during the procedure. This fine artery was immediately repaired using the bipolar coagulation technique without producing vascular stenosis, collapse, or thrombosis (Figure 5) (see Video, Supplemental Digital Content 2, illustrating the bipolar coagulation technique to repair an inadvertently damaged small left temporal M2-M3 branch).

\section{DISCUSSION}

When the vessel has a medium or large caliber and the wall defect is not small, methods for definitive repair include microsuture, microvascular clip placement, AnastoClips, wrapping, and bypass technique. ${ }^{9-12}$ However, all of these procedures are not so useful when the lesion is particularly fine and/or the vessel especially tiny.

In such circumstances, the ability of accomplishing precise hemostasis without harming the surrounding neurovascular structures is of utmost importance. In this regard, the development of electrosurgery played a key role. In the 1920s Bovie developed his original foot pedal-operated monopolar electrosurgical unit, which was rapidly appreciated and largely adopted by Cushing. ${ }^{24}$

In 1940, Greenwood introduced the use of a 2-point coagulation system. ${ }^{25-27}$ This concept was later improved by Malis, who designed a bipolar coagulator by combining a spark gap generator with surgical forceps, which causes no current spread or radiation of heat to surrounding tissue. ${ }^{28-30}$ The availability of such focused bipolar coagulation allowed doctors to take full advantage of the operating microscope and contributed to the further development of microsurgical techniques.

In 1996 Professor Yasargil described the use of the bipolar forceps for microsurgical vascular reconstruction, which had being used since the 1960s. In the original technique, suction and compression with a cottonoid are used to control the bleeding so as to identify the exact location of the vessel wall defect. Next, the small tear is sealed using bipolar forceps with sharp tips $(0.3 \mathrm{~mm})$ for a delicate coagulation (15-20 Malis units, 1.6-3 W). If the bleeding is not completely halted, temporary microvascular clips are placed (the proximal one first, then the distal clip, if necessary) to coagulate the defect. ${ }^{1,31}$

Our technique for microvascular repair takes advantage of high magnification of the operating microscope $(10-15 \times)$ to identify the bleeding site. The usefulness of such 3D-magnified vision is clearly evident, even more evident increasing the magnification above those values. ${ }^{13,15}$

Contrary to Professor Yasargil's original method, in our modification sponges or cottonoids, which could restrict the working 


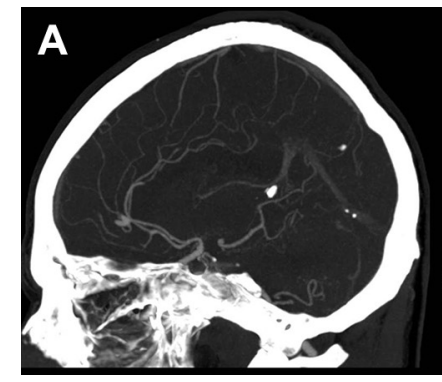

Figure 4. Sagittal preoperative computed tomography (CT) angiography image revealing a right pericallosal artery aneurysm (A). Sagittal postoperative CT scans

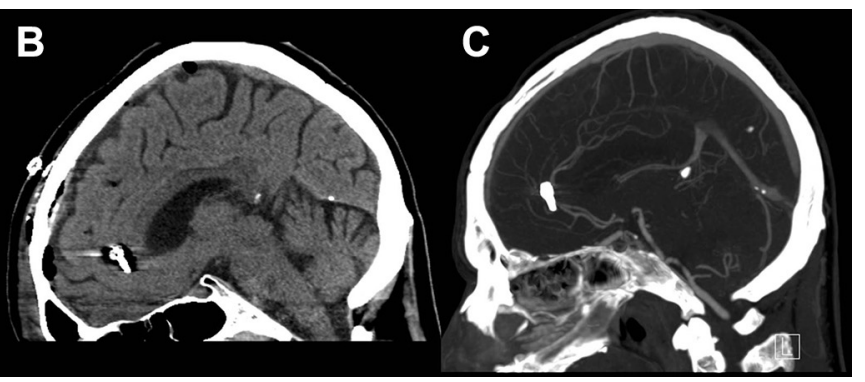

showing a complete clipped aneurysm without evidence of hemorrhage or ischemia (B and $\mathbf{C}$ ). area, are not routinely used to compress the vessel wall defect. Instead, we prefer a careful suction. In this regard, adjusting the strength of the suction by sliding the thumb over the 3 holes in the handle is extremely helpful. This, along with a focused saline irrigation, when necessary, guarantees achieving an optimal control of bleeding in most cases. However, as proposed by Yasargil, a small sponge may be extremely useful to gently turn the artery when the bleeding site is on the contralateral wall of the vessel. ${ }^{1,31}$ In addition, in these circumstances the vessel wall defect may be safely and effectively sealed by using angled bipolar forceps.

Moreover, no microvascular clip is regularly used in our modification. Hence, there is no potential dangerous occlusion time. Instead, the blood tear from the injured zone helps us to identify and coagulate the wall defect, making a sealant with the blood components going through the hole. In addition, the blood tear also works as a fine irrigation between the bipolar tips, preventing them from sticking during the coagulation.

A high-quality microsurgical technique may prevent the "sticking" of bipolar tips after coagulation, allowing surgeons to get good results with cheap, regular forceps. These forceps are, in most cases, the only ones available in developing countries where the nonstick bipolar forceps or even disposable ones are out of the health care system's budget.

Furthermore, keeping the flow inside the vessel may preserve the normal diameter of the artery during the procedure and may theoretically reduce the risk of a stenosis or an intraluminal collapse.

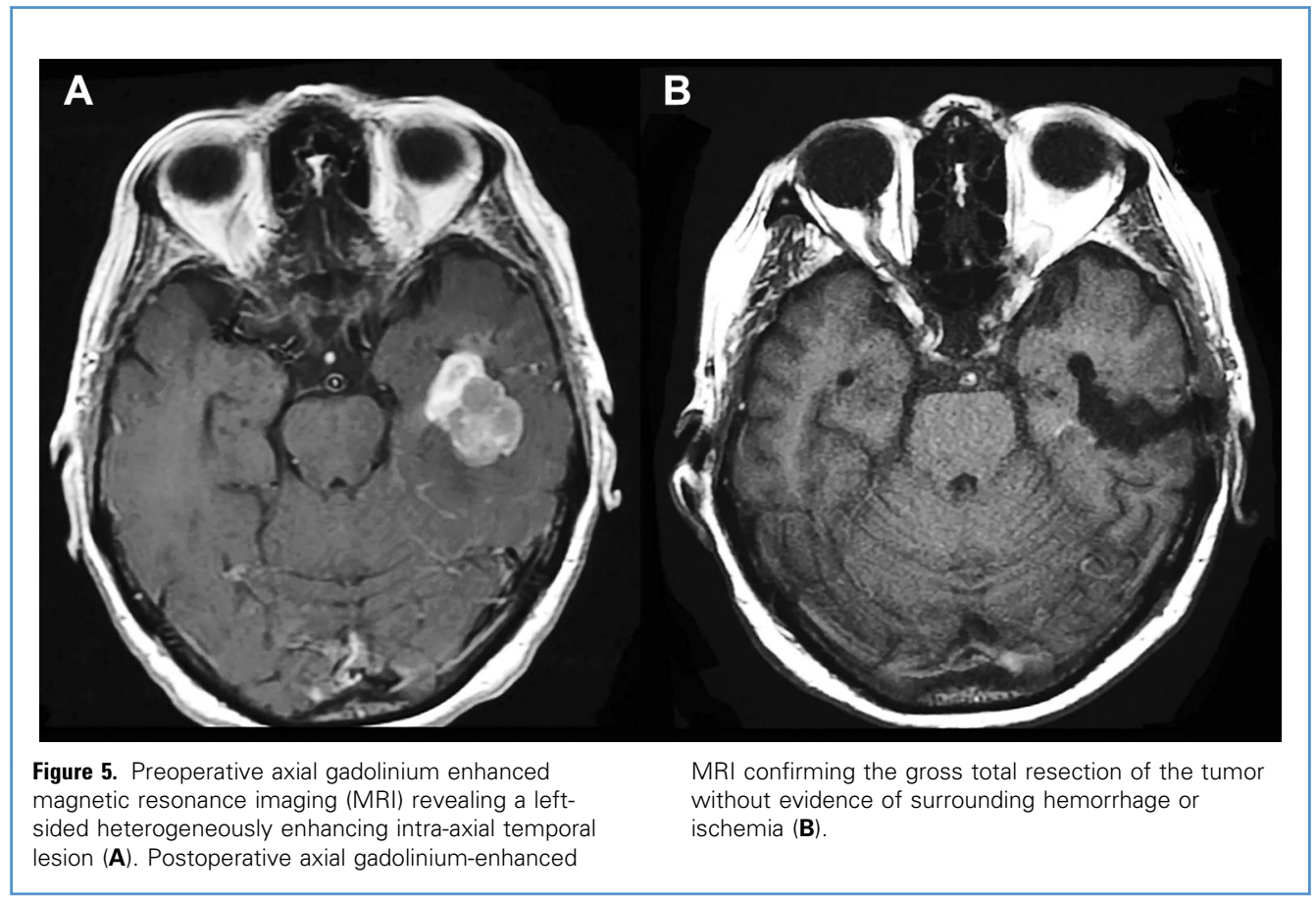


In our experience, a bipolar power setting of 20 (sharp) to 25 (blunt) Malis units ( 3 and $5 \mathrm{~W}$, respectively) may allow us to get good results. Lower intensities are usually insufficient for good control.

Potential hazards for this technique are the following:

1). The complete coagulation of the injured artery produced by accidentally hugging the fine vessel between the tips of the bipolar; this will determine a definitive arterial damage with a consequent occlusion and a possible cerebral infarct.

2). An imprecise positioning of the bipolar tips while repairing the bleeding site of a medium caliber and atherosclerotic vessel may injury the normal arterial surface adjacent to the defect, enlarging it and making impossible its repair.

3). An inadequate control of the suction power may produce catastrophic consequences.

4). An alternative technique, seldom needed in our practice, is to apply and compress hemostatic agents around the lesion. However, with this more time-consuming option, the surgical field becomes dirty. Moreover, it is not safe under high magnification as the anatomic structures are hidden behind the same hemostatic agents.

A careful and meticulous application of the bipolar coagulation technique may help to avoid all the previously mentioned complications.

Nonetheless, only constant training under high magnification allows surgeons to develop the microsurgical skills and manual dexterity that are required to master this technique with care and precision. $^{32}$ On the other hand, a judicious application of microsurgical principles may reduce complication rates and the need to use such a technique.

To summarize, as mentioned earlier, the bipolar coagulation technique is indicated when the lesion is particularly fine and/or the vessel is especially tiny. For damaged proximal arterial branches, this technique is not recommended and we prefer to use microsuture, microvascular clip placement, AnastoClips, wrapping, or the bypass technique. Similarly, if the vessel wall defect is wider than $5 \%$ to $10 \%$ of the vessel diameter and/or the ratio between the laceration and vessel wall thickness is relatively high, other solutions may be required because the bipolar coagulation technique may not be as effective and may even be dangerous.

In our experience, a correct indication for use of the bipolar coagulation technique (i.e., small wall defects in fine arteries accidently damaged during a microsurgical operation) was not frequent, about 3 to 4 cases/year. In these circumstances, the bipolar coagulation technique allowed us to safely restore the functional integrity of the vessel wall in $95 \%$ of the cases. Moreover, when the bipolar technique was employed, no postoperative related clinical complication was detected. In addition, in $95 \%$ of the cases no luminal stenosis was evident at postoperative radiologic controls. A radiographic arterial narrowing, without any correlated clinical symptom, was demonstrated in only $5 \%$ of cases.

In the remaining $5 \%$ of cases, proximal control using microvascular clips was required in order to apply the bipolar coagulation technique, or alternative solutions were needed to seal the vessel wall defect (such as wrapping with hemostatic agents or fine stitches). At times, if proximal control was difficult to reach and/or the risk of consequent neurologic deficits was too high, coagulation with adhered tumor tissue or a small piece of sponge was useful to seal the hole and avoid laceration.

\section{CONCLUSIONS}

In summary, the bipolar coagulation technique represents a safe, clean, fast, and even cheap method to repair wall defects in fine arteries that are accidently damaged during a microsurgical operation. Hence we believe that this relatively simple technique, borne out by years of experience, should be a useful adjunct in the neurosurgical armamentarium.

\section{REFERENCES}

I. Yaşargil MG. A legacy of microneurosurgery: memoirs, lessons, and axioms. Neurosurgery. I999; 45:I025-I092.

2. Hernesniemi J, Niemelä M, Karatas A, Kivipelto L, Ishii K, Rinne J, et al. Some collected principles of microneurosurgery: simple and fast, while preserving normal anatomy: a review. Surg Neurol. 2005;64:195-200.

3. Velasquez JC, Lau J, Kozyrev D, Sharafeddin F, Colasanti R, Luostarinen T, et al. Clean, fast and preserving normal anatomy: "the Helsinki revolution" in microneurosurgery. J Neurosurg Sci. 2016; 6o: $44-53$.

4. Drake CG, Peerless SJ, Hernesniemi JA. Surgery of Vertebrobasilar Aneurysms. London, Ontario Experience on 1767 Patients. Vienna: Springer-Verlag; I996.

5. Yaşargil MG. Personal considerations on the history of microneurosurgery. J Neurosurg. 20I0;II2: II63-II75.
6. Peerless SJ, Hernesniemi JA, Gutman FB Drake CG. Early surgery for ruptured vertebrobasilar aneurysms. J Neurosurg. I994;80: $643-649$.

7. Ha S-K, Lim DJ, Seok BG, Kim SH, Park JY, Chung YG. Risk of stroke with temporary arterial occlusion in patients undergoing craniotomy for cerebral aneurysm. J Korean Neurosurg Soc. 2009;46: 3I-37.

8. Hernesniemi J, Niemelä M, Dashti R, Karatas A, Kivipelto L, Ishii K, et al. Principles of microneurosurgery for safe and fast surgery. Surg Technol Int. 2006;15:305-310.

9. Park J. Maintenance of cerebral blood flow during microsuture repair of the superior wall of the intracranial internal carotid artery. World Neurosurg. 2013;80:436.eI-436.e5.

Io. Regelsberger J, Matschke J, Grzyska U, Ries T, Fiehler J, Köppen J, et al. Blister-like aneurysmsa diagnostic and therapeutic challenge. Neurosurg Rev. 20II;34:409-4I6.
II. Romani R, Kivisaari R, Celik O, Niemelä M, Perra G, Hernesniemi J. Repair of an alarming intraoperative intracavernous carotid artery tear with anastoclips: technical case report. Neurosurgery. 2009;65:E998-E999 [discussion: E999].

I2. Joo S-P, Kim T-S, Moon K-S, Kwak H-J, Lee J-K, Kim J-H, et al. Arterial suturing followed by clip reinforcement with circumferential wrapping for blister-like aneurysms of the internal carotid artery. Surg Neurol. 2006;66:424-428.

I3. Yaşargil MG. Intracranial microsurgery. Proc R Soc Med. I972;65:I5-I6

I4. Yasargil MG, Vise WM, Bader DC. Technical adjuncts in neurosurgery. Surg Neurol. 1977;8:33I-336.

15. Matsumura N, Shibata T, Hori E, Kamiyama H, Tani $\mathrm{M}$, Okamoto S, et al. An operating microscope with higher magnification and higher resolution for cerebral aneurysm surgery: preliminary experience-technical note. Neurol Med Chir (Tokyo). 20I4;54:497-50I. 
I6. Elsharkawy A, Niemelä $M$, Lehečka $M$, Lehto $H$, Jahromi B-R, Goehre F, et al. Focused opening of the sylvian fissure for microsurgical management of MCA aneurysms. Acta Neurochir (Wien). 2014;156: I7 -25 .

I7. Hernesniemi J. Mechanisms to improve treatment standards in neurosurgery, cerebral aneurysm surgery as example. Acta Neurochir Suppl. 200I;78: I27-I34.

I8. Mikami T, Wanibuchi M, Mikuni N. Bumping phenomenon during continuous coagulation with bipolar forceps. Neurol Med Chir (Tokyo). 2012;52: 73I- 735

I9. Ferguson RL, Jobe K. A quiet hand for microneurosurgery: twiddle your thumb. Technical note. J Neurosurg. 2004;I0I:54I-544.

20. Vellimana AK, Sciubba DM, Noggle JC, Jallo GI. Current technological advances of bipolar coagulation. Neurosurgery. 2009;64(suppl 3):onsis-onsi8.

2I. Dashti R, Laakso A, Niemelä M, Porras M, Hernesniemi J. Microscope integrated indocyanine green video-angiography in cerebrovascular surgery. Acta Neurochir Suppl. 20II;I09:247-250.

22. Gruber A, Dorfer C, Standhardt H, Bavinzski G, Knosp E. Prospective comparison of intraoperative vascular monitoring technologies during cerebral aneurysm surgery. Neurosurgery. 2011;68:657-673.

23. Dashti R, Hernesniemi J. Intraoperative assess ment of a quality of microneurosurgical clipping role of indocyanine green videoangiography. World Neurosurg. 20I4;82:e589-e59o.

24. Cushing H, Bovie WT. Electro-surgery as an aid to the removal of intracranial tumors. With a preliminary note on a new surgical-current generator. Surg Gynec Obstet. I928;47:75I-785.

25. Greenwood J Jr. Two point coagulation. A new principle and instrument for applying coagulation current in neurosurgery. Am J Surg. I940;50: 267-270

26. Greenwood J Jr. Two point coagulation: a followup report of a new technic and instrument for electrocoagulation in neurosurgery. Arch Phys Ther. I942;23:552-554.

27. Greenwood J Jr. Two-point or interpolar coagulation; review after a twelve-year period with notes on addition of a sucker tip. J Neurosurg. I955;I2 I96-I97.

28. Malis LI. Instrumentation and techniques in microsurgery. Clin Neurosurg. I979;26:626-636.
29. Malis LI. Electrosurgery. Technical note. J Neurosurg. I996;85:970-975.

30. Malis LI. Electrosurgery and bipolar technology. Neurosurgery. 2006;58(suppl I):ONSI-ONSi2.

3I. Yasargil MG. Microneurosurgery, Volume IVB: Microneurosurgery of CNS Tumors. New York: Georg Thieme Verlag; I996.

32. Kivelev J, Hernesniemi J. Four-fold benefit of wound closure under high magnification. Surg Neurol Int. 2013;4:II5.

Professor Juha Hernesniemi is an Aesculap counselor. The authors have no personal financial or institutional interest in any of the drugs, materials, and devices described in this article.

Received 24 April 2016; accepted 6 June 2016

Citation: World Neurosurg. (2016) 93:324-329. http://dx.doi.org/10.1016/j.wneu.2016.06.013

Journal homepage: www.WORLDNEUROSURGERY.org Available online: www.sciencedirect.com

1878-8750/\$ - see front matter (C) 2016 Elsevier Inc. All rights reserved.

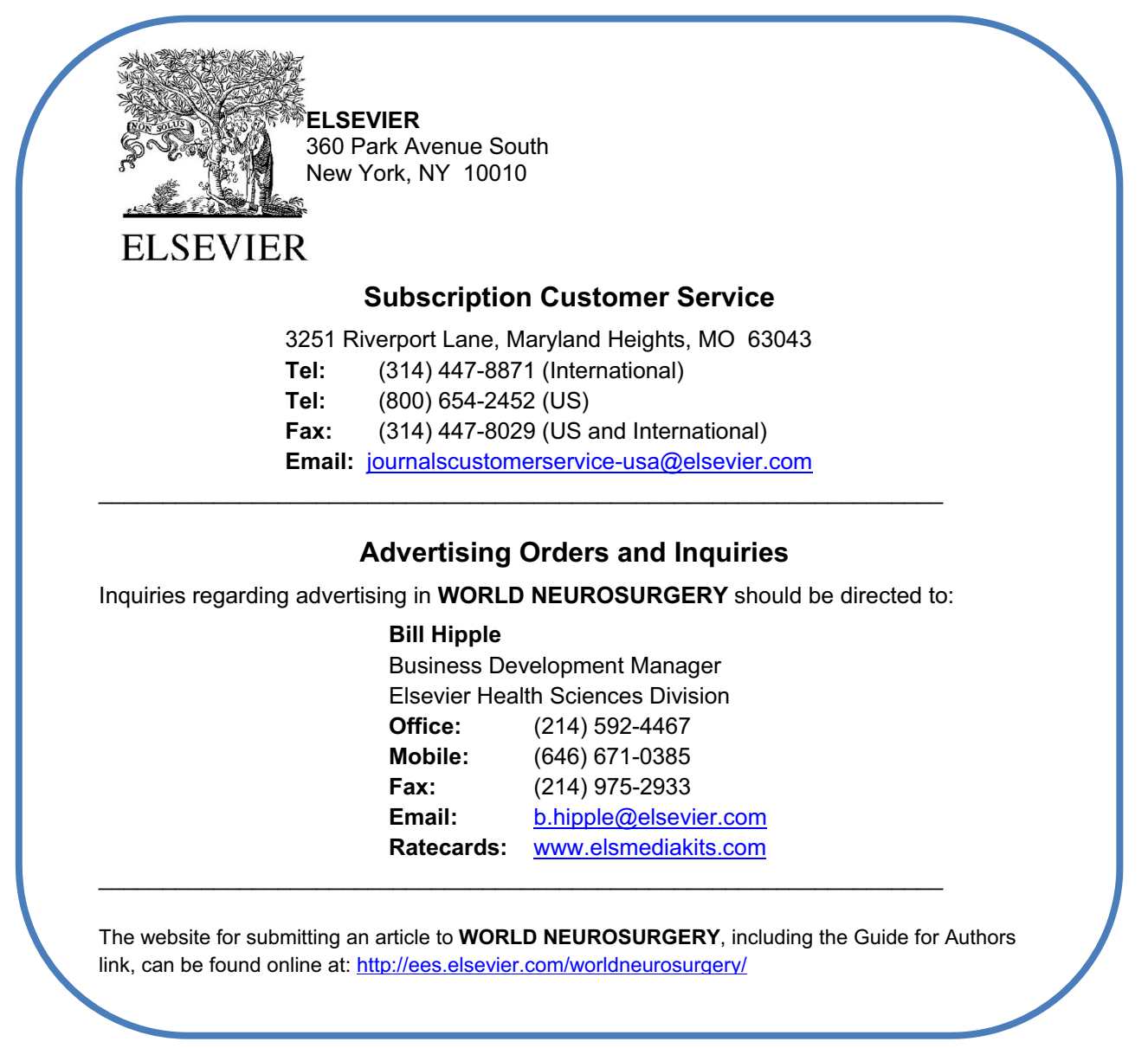

